\title{
Hemopexins Suppress Phorbol Ester-induced Necrosis of Polymorphonuclear Leucocytes
}

\author{
Kingo Suzuki*, Hidenobu Kato, Yasuyuki Sakuma, and Hideo Namiki \\ Department of Biology, School of Education, Waseda University, Shinjuku-ku, Tokyo 169-0051, Japan
}

\begin{abstract}
It was recently reported that intravenous administration of phorbol 12-myristate 13-acetate (PMA) showed a therapeutic effect in myelocytic leukemia patients. However, we previously observed that, in serum-free conditions, polymorphonuclear leucocytes (PMNs) were killed rapidly by exposure to PMA, suggesting the possibility of serious side effects. In this study, we found that PMA-induced necrosis of PMNs was prevented by serum, suggesting the existence of a "necrosis-suppressing factor". Next we tried to identify the serum factor. The hemopexins we purified were found to suppress necrosis of PMNs in a dose-dependent fashion. Hemopexins alone could not suppress necrosis, however, as it required the coexistence of another macromolecule such as albumin. Albumin promoted the suppressive activity of hemopexins in a dose-dependent fashion. These results strongly suggest that serum hemopexins may rescue mature PMNs from necrosis in the PMA-administered leukemia patient as previously reported, resulting in avoidance of serious side effects.
\end{abstract}

Key words: hemopexin/phorbol 12-myristate 13-acetate/necrosis/polymorphonuclear leucocytes

The protein kinase $\mathrm{C}$ activator phorbol 12-myristate 13-acetate (PMA) is known to induce differentiation of cultured human promyelocytic leukemia cells such as HL-60 to macrophage-like cells in vitro (Shimizu et al., 1991; Aihara et al., 1991; Qin and Yamamura, 1997). PMA has thus been expected to be a potentially useful therapeutic agent for patients with myelocytic leukemia who are refractory to other chemotherapeutic drugs. Recently it was reported that intravenous administration of PMA alone or in combination with other chemotherapeutic drugs showed a therapeutic effect: myeloblasts in the bone marrow and peripheral blood were decreased and white blood cells and neutrophils were increased (Han et al., 1998a; Han et al., 1998b).

On the other hand, the exposure of polymorphonuclear leucocytes (PMNs) to any activating agent such as PMA, is reported to trigger "microbicidal events" including superoxide generation and release of microbicidal enzymes (Curnutte et al., 1987; Guigui et al., 1988). Because these bacterial killing systems are nonspecific, they may also be toxic for the host organism. In fact, we previously observed

*To whom correspondence should be addressed: Department of Biology, School of Education, Waseda University, Shinjuku-ku, Tokyo 169-0051, Japan.

Tel: +81-3-3203-8449, Fax: +81-3-3207-9694

E-mail: kingo@mn.waseda.ac.jp

Abbreviations: PMA, phorbol 12-myristate 13-acetate; PMNs, polymorphonuclear leucocytes. that, in serum-free conditions, PMNs but not lymphocytes killed themselves within 3 to 5 hours after exposure to PMA (Suzuki and Namiki, 1998), with cell death being necrotic and specific for PMNs. If the event we observed also occurs in vivo, the clinical studies on the therapeutic effect of PMA intravenous infusions described above (Han et al., 1998a; Han et al., 1998b) would probably have ended in failure. A possible explanation is that there is a factor in serum or in whole blood that suppresses the PMA-induced necrosis of PMNs.

In this study, we observed that, in the presence of serum, PMA-induced necrosis of PMNs did not occur, suggesting the existence of a "necrosis-suppressing factor" in serum. We next tried to identify the factor. Serum hemopexins were found to inhibit the PMA-induced necrosis of PMNs.

\section{Materials and Methods}

\section{Materials}

PMA, human serum, bovine $\alpha$ - and $\gamma$-globulins, bovine transferrin, human albumin (approx. 99\%, globulin free, fatty acid free), cytochrome $c$, 6,9-diamino-2-ethoxyacridine lactate (rivanol), heminagarose beads, and dextran (MW66700) were from Sigma Chemical Co., St. Louis, MO, USA. Hemin chloride and human $\alpha$-globulins were from ICN Biomedicals Inc., Costa Mesa, CA, USA. BSA (min. 98\%, fatty acid free) and human $\gamma$-globulins were from 
Wako Pure Chemical Co., Tokyo, Japan. Fetal bovine serum was from Iwaki Glass, Funabashi, Japan. Porcine serum was prepared from whole peripheral blood. Trypan blue was from Merck, Darmstadt, Germany. DEAE-Toyopearl 650S gel was from Toyo Soda Mfg. Co., Tokyo, Japan. Prestained protein molecular weight markers was from Bio-Rad Laboratories, Hercules, CA, USA. Bovine fetuin was from Calbiochem-Novabiochem Co., La Jolla, CA, USA. Rabbit anti-human hemopexin polyclonal antibodies were from Medical \& Biological Laboratories Co., Nagoya, Japan. All other chemicals were of analytical grade.

\section{Preparation of PMNs}

PMNs were isolated from porcine peripheral blood as described previously (Suzuki and Namiki, 1998). Cells were suspended in ice cold PBSG $\left(\mathrm{Ca}^{2+}-, \mathrm{Mg}^{2+}\right.$ - free phosphate buffered saline, $\mathrm{pH}$ 7.4 , containing $5 \mathrm{mM}$ glucose) at $6 \times 10^{7}$ cells $/ \mathrm{ml}$ and used for experiments immediately.

\section{Measurement of PMN superoxide production}

Superoxide was measured as the rate of superoxide dismutaseinhibitable reduction of cytochrome $c$ as described previously (Suzuki and Namiki, 1998).

\section{Incubation of PMNs with various agents}

Cell incubations with various agents except whole sera were performed at $3 \times 10^{6} \mathrm{cells} / \mathrm{ml}$ in the incubation medium (PBSG containing $40 \mathrm{mg} / \mathrm{ml} \mathrm{BSA}$ ) containing each test sample unless otherwise specified. In the case of whole serum, cells were directly suspended in serum followed by incubation. After the cells were precipitated by centrifugation, cells and supernatant were used for trypan blue exclusion test and LDH viability assay, respectively (see below).

\section{Cytotoxicity assay}

Cell viability was assessed by trypan blue exclusion test and by the LDH (lactate dehydrogenase) assay. The LDH assay kit (Wako Pure Chemical Co.) was used according to the manufacturer's instructions. Unless otherwise specified, results of the LDH assay were expressed as relative LDH-release (\%) by PMNs, with the LDH activity released by PMNs suspended in the incubation medium described above and killed by exposure to $100 \mathrm{ng} / \mathrm{ml}$ PMA for 5 hours ("medium alone") being regarded as $100 \%$.

We show the results of the LDH assay as cell viability in this paper, but because whole serum often contained endogenous LDH activity, we could not use the LDH assay in these cases. In the other cases, we confirmed all the data of the LDH assay were consistent with those of the trypan blue exclusion assay.

\section{Hemopexin purification from human, bovine, and porcine serum}

Serum hemopexins were purified by conventional methods using rivanol precipitation followed by hemin-agarose affinity chroma- tography and anion exchange chromatography (Muller-Eberhard, 1988; Tsutsui, 1986; Strop et al., 1981; Majuri, 1982; Suttnar et al., 1979). Ten $\mathrm{ml}$ serum of which the $\mathrm{pH}$ was adjusted to 8.0 with $\mathrm{NaOH}$ was mixed gradually with equivalent volume of cold $1.68 \%$ rivanol solution ( $\mathrm{pH} 8.0)$ and gently stirred for $5 \mathrm{~h}$ at $4^{\circ} \mathrm{C}$ in order to precipitate and remove rivanol-albumin complex. Free rivanol in the supernatant was precipitated by centrifugation following addition of $5 \% \mathrm{NaCl}$. For hemin-agarose affinity chromatography, the above rivanol-supernatant was dialyzed against PBS. The supernatant was applied to $2 \mathrm{ml}$ of a hemin-agarose column three times. The column was washed thoroughly with PBS containing $0.5 \mathrm{M} \mathrm{NaCl}$ to remove unbound proteins. Proteins containing apohemopexins bound to the column were eluted by $0.2 \mathrm{M}$ citric acid (pH 2.0). Protein elution was monitored by UV absorption at 280 $\mathrm{nm}$. Proteins were buffer-exchanged for 0.01M Tris- $\mathrm{HCl}(\mathrm{pH} 7.0)$, and applied to $2 \mathrm{ml}$ of a DEAE-Toyopearl column. After washing with $0.01 \mathrm{M}$ Tris- $\mathrm{HCl}$ buffer extensively, Hemopexins were eluted by $0.01 \mathrm{M}$ Tris- $\mathrm{HCl}(\mathrm{pH} 7.0)$ containing $0.4 \mathrm{M} \mathrm{NaCl}$, which was dialyzed and lyophilized for each analysis.

\section{Protein measurement}

Protein concentrations were determined by Bio-Rad protein assay kit, with BSA used as the standard protein.

\section{SDS-PAGE and immunoblot analysis}

Proteins were separated by $10 \%$ SDS polyacrylamide gel electrophoresis under denaturing conditions, blotted onto Immobilon ${ }^{\mathrm{TM}}$ membrane (Millipore) and used for each analysis as described below. For protein detection, the membranes were stained with Coomassie Brilliant Blue. For detection of hemopexin, they were probed with rabbit anti-human hemopexin antibodies followed by HRP-conjugated goat anti-rabbit Ig. DAB color reaction was used for visualization of the protein bands.

\section{$N$-terminal amino acid sequencing of proteins}

$\mathrm{N}$-terminal amino acid sequencing was performed on an Applied Biosystems Japan 494-cLC sequencer after being blotted to and excised from Immobilon ${ }^{\mathrm{TM}}$ membrane.

\section{Results and Discussion}

After PMNs are exposed to any activating agent such as PMA, "microbicidal events" occur, including superoxide generation and release of microbicidal enzymes (Curnutte et al., 1987; Guigui et al., 1988). While these events are obviously vital for host defense, these bacterial killing systems are nonspecific, and activated PMNs have been implicated in host tissue damage in a variety of diseases of diverse pathogenesis. Previously we observed that, under serumfree conditions, PMNs were killed within 3 to 5 hours after exposure to PMA (Suzuki and Namiki, 1998), although the mechanism of induction of necrosis is at present unknown. If the event we observed also occurs in vivo, the clinical 
studies on the therapeutic effect of intravenous infusions of PMA described above (see Introduction) would probably have been unsuccessful. A possible explanation is that there is a factor in serum or in whole blood that suppresses the PMA-induced necrosis of PMNs.

In this study, therefore, we tested the effect of serum on PMA-induced necrosis (Fig. 1). Interestingly, PMNs suspended in fetal bovine serum (FBS) survived well when exposed to PMA for 5 hours. This result convinced us that a serum factor exists that rescues PMNs from the toxicity of PMA. We also observed that human and porcine serum could suppress the PMA-induced necrosis of PMNs. Therefore, we tried to isolate and identify the suppressive factor from serum.

In initial experiments, FBS was subjected to ultrafiltration through Millipore XM50 size exclusion membranes (MW cut-off 50000). No necrosis-suppressing activity passed through the membrane, but activity was recovered from its surface (data not shown). This result suggests that the suppressive factor is not a free small molecule. Albumin, the most abundant serum protein (about 40-50 $\mathrm{mg} / \mathrm{ml}$ of serum) and which is included in the incubation medium at $40 \mathrm{mg} / \mathrm{ml}$, was unable to suppress necrosis (Fig. 1).

Among a variety of molecules in serum, we focused on hemopexin as a candidate for the necrosis-suppressing

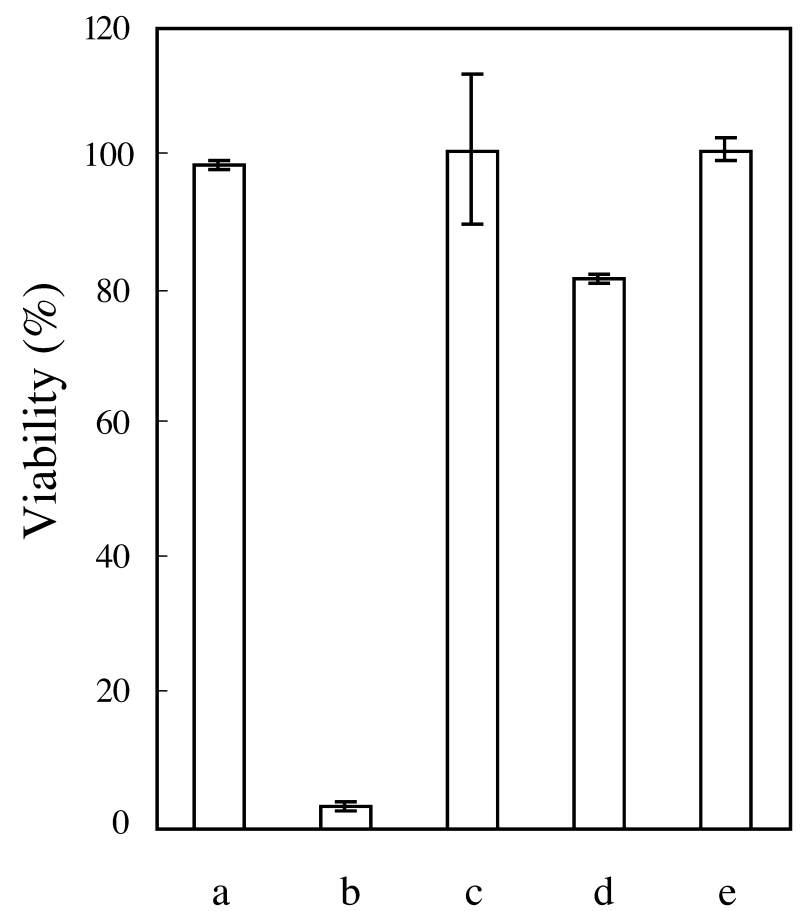

Fig. 1. Effect of serum on PMA-induced necrosis of PMNs. Cells were suspended in incubation medium ( $a$ and b) or in serum (c, $d$ and e represent fetal bovine, human and porcine, respectively) and incubated in the absence (a) or presence (b-e) of $100 \mathrm{ng} / \mathrm{ml}$ PMA for 5 hours. Viability (\%) was assessed by trypan blue exclusion test. Results are expressed as mean $\pm \mathrm{SD}$ of three separate experiments. factor described above. This idea is based on the following information about the characteristics and physiological roles of hemopexin.

Hemopexin is a heme-binding serum glycoprotein, of which the serum concentration ranges from 0.4 to $1.5 \mathrm{mg} / \mathrm{ml}$ (Muller-Eberhard, 1988). Hemopexin is known to play an important role in receptor-mediated cellular heme uptake; for example, hemopexin is implicated in the system that delivers heme to the liver cells via a receptor-mediated process (Smith and Morgan, 1985; Wu and Morgan, 1994). The hemopexin receptor is also found in other tissues or cells such as placenta, human acute T-lymphoblastic (MOLT-3) cells and human PMNs (Taketani et al., 1987; Smith et al., 1997; Okazaki et al., 1989). Hemopexin has been studied for its role in heme-mediated functions. Gutteridge et al. (Gutteridge and Smith, 1988) reported that hemopexin functions as an extracellular antioxidant, and it may have a role in the body's defense mechanisms. Hemopexin inhibits heme-mediated lipid peroxidation by binding extracellular free heme (Gutteridge and Smith, 1988). Balla et al. found that endothelial cells in vitro rapidly incorporate free heme, and that the heme loading sensitizes the endothelium to oxidant-mediated cytotoxicity caused by hydrogen peroxide released by activated PMNs; that the heme-aggravated cytotoxicity closely parallels amplified lipid peroxidation in endothelial cell membranes; and that hemopexin, by trapping heme, protects endothelial cells from activated PMNs (Balla et al., 1990).

Although it is unknown whether heme molecules are released extracellularly by PMA-exposed PMNs, it may be possible that membrane or secreted hemoproteins release free heme into the extracellular milieu by oxidative breakdown, resulting in self-damage of PMA-exposed PMNs caused by heme-aggravated oxdative cytotoxicity. We hypothesized that hemopexin may interfere with these processes.

Consequently, we decided to examine whether hemopexin suppresses PMA-induced necrosis of PMNs. Because purified or recombinant hemopexin is not commercially available, we had to purify it ourselves. Many investigators have purified hemopexin from the serum of several animal species by using simple hemin-affinity chromatography (Muller-Eberhard, 1988; Tsutsui, 1986; Strop et al., 1981; Majuri, 1982; Suttnar et al., 1979; Takahashi et al., 1985a; Olsen, 1986). We decided to purify hemopexin from human serum for two reasons: 1) the complete amino acid sequence of human hemopexin is known, and 2) we could obtain rabbit anti-human hemopexin polyclonal antibodies, allowing easy identification of purified human hemopexin. We could not obtain any information about the amino acid sequence of bovine hemopexin.

The most efficient procedure to remove a large amount of albumin may be the rivanol (6,9-diamino-2-ethoxyacridinelactate) precipitation method, by which rivanol forms an insoluble complex with albumin (Muller-Eberhard, 1988; 
Tsutsui, 1986; Strop et al., 1981; Majuri, 1982). The rivanol supernatant prepared from human serum was applied to hemin-agarose affinity chromatography as described in Materials and Methods. The column-bound protein fractions were collected. The preparations obtained were of high purity and contained only a small amount of immunoglobulins, as determined by SDS-PAGE followed by N-terminal amino acid sequencing of the CBB-stained protein bands (data not shown). Contaminating immunoglobulins can be removed by anion-exchange chromatography on a DEAE-cellulose column (Strop et al., 1981; Majuri, 1982; Suttnar et al., 1979). We performed DEAE-Toyopearl column chromatography, and fractions bound to the column were collected. SDS-PAGE followed by CBB staining revealed doublet protein bands of about 74.5 and $71 \mathrm{kDa}$ and a negligible band of $52 \mathrm{kDa}$ (Fig. 2a). The N-terminal amino acid sequence of the major $74.5 \mathrm{kDa}$ band was determined to be N-XPLPPTSAHGNVAEG, which is identical to that of human hemopexin (Swiss-Prot protein data base, accession number P02790), in which the N-terminal amino acid should be Thr and may be carbohydrate-modified. Immunoblot analysis showed that these doublet bands, as well as the faint $52 \mathrm{kDa}$ band (which was also found to be a doublet of 52 and $49.5 \mathrm{kDa}$ ), reacted with anti-human hemopexin antibodies (Fig. 2b). It is likely that the appearance of doublet bands is caused by the molecular heterogeneity of hemopexin, such as different numbers and/or types of oligosaccharide chains; the 52 and $49.5 \mathrm{kDa}$ doublet may be unglycosylated hemopexin (Noiva et al., 1987; Takahashi et al., 1985b). We used the DEAE-Toyopearl-bound proteins as hemopexins in this study.

Next, we examined whether or not these purified human hemopexins could suppress the PMA-induced necrosis of PMNs. Interestingly, human hemopexins suppressed PMN necrosis in a dose-dependent fashion (Fig. 3). Bovine or porcine hemopexin fraction purified by the same methods also had similar activity (data not shown). The purified hemopexins are apo-hemopexins, because the heminagarose column binds only apo-hemopexins. As described above, hemopexin is known for its heme-mediated functions. We observed that heme $(20-100 \mu \mathrm{M})$ by itself could not induce PMN necrosis (data not shown). However, it is possible that hemopexins rescue PMNs from PMAinduced necrosis by trapping heme molecules, resulting in suppression of heme-aggravated cytotoxicity. If this is the case, the necrosis-suppressive activity of hemopexins may be impaired by exogenous addition of excess amounts of heme. Therefore, we examined if hemopexins could also suppress necrosis of PMNs in the presence of exogenous heme. Hemopexins ( $2 \mathrm{mg} / \mathrm{ml}$ in PBSG) were incubated with $100 \mu \mathrm{M}$ of hemin chloride for 60 minutes at $37^{\circ} \mathrm{C}$, and were then used for the viability assay. To our surprise, hemeloaded hemopexins were able to suppress the PMA-induced necrosis, although the activity was slightly less than that of apo-hemopexins (Fig. 4). These results show that apohemopexins at physiological concentrations inhibit necrosis of PMA-exposed PMNs and, unexpectedly, that hemopexins suppress necrosis even in the presence of $100 \mu \mathrm{M}$ heme a)

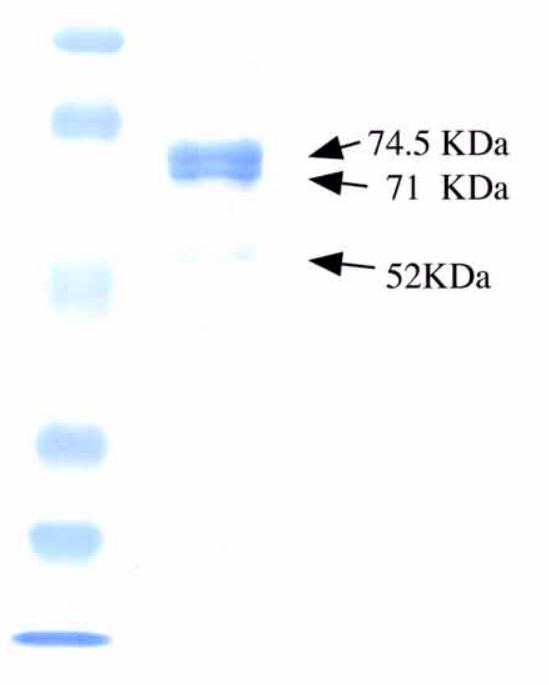

b)

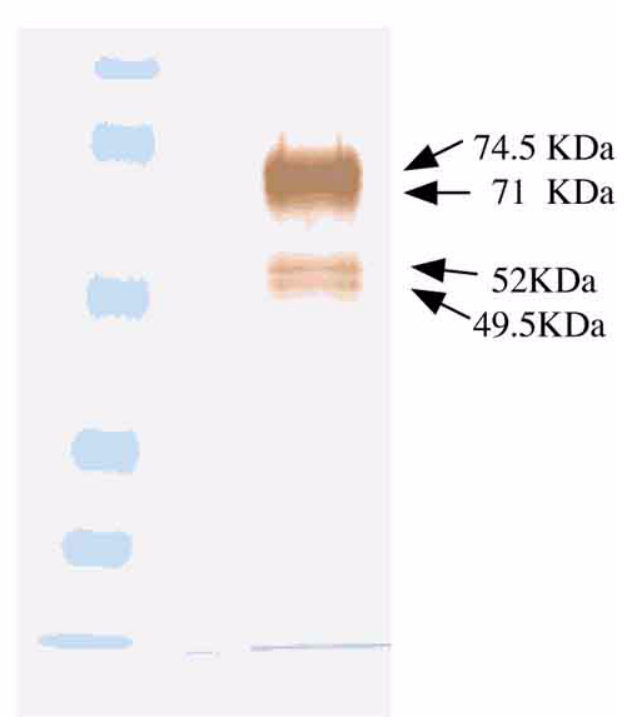

Fig. 2. SDS-PAGE and immunoblot analysis of purified human hemopexins. Proteins ( $2 \mu \mathrm{g}$ and $1 \mu \mathrm{g}$ in a and b, respectively) eluted from a DEAEToyopearl column were separated by SDS-PAGE followed by (a) CBB-staining or (b) immunoblotting with anti-human hemopexin antibodies as described in Materials and Methods. Protein bands in the left lanes in (a) and (b) are molecular weight markers. 


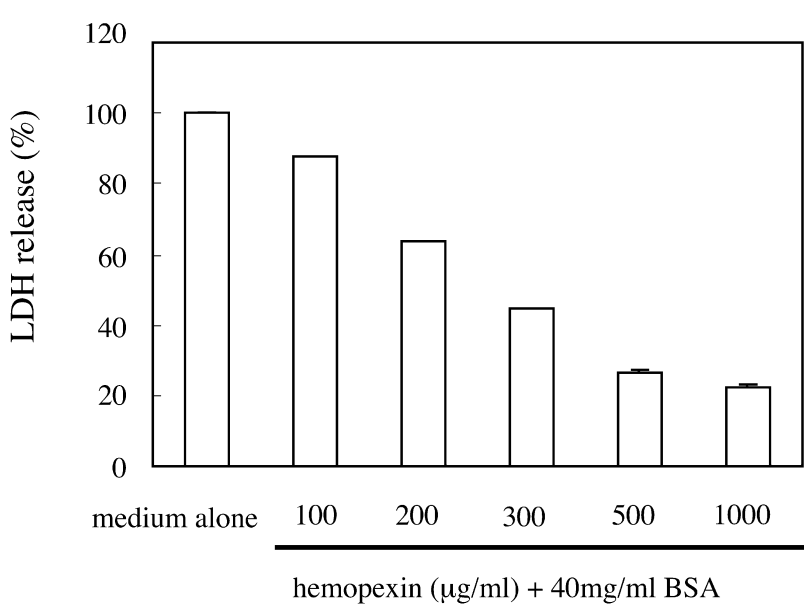

Fig. 3. Suppression of PMA-induced PMN necrosis by hemopexins: effect of concentration of hemopexins or BSA. Cells were exposed to $100 \mathrm{ng} / \mathrm{ml}$ PMA for 5 hours in the presence of $40 \mathrm{mg} / \mathrm{ml} \mathrm{BSA}$ and variable concentrations $(0,0.1,0.2,0.4,0.6$, and $1.0 \mathrm{mg} / \mathrm{ml})$ of hemopexins. Cell viability was assessed by LDH assay. Results are expressed as mean \pm SD of three separate experiments.

(Fig.4), the concentration of which is high enough to saturate the $2 \mathrm{mg} / \mathrm{ml}$ of apo-hemopexins. Thus, the inhibition by hemopexin of PMA-induced necrosis of PMNs observed in this study may not be related to heme binding (trapping).

It is possible that hemopexins could trap the added PMA before it acts on cells, resulting in avoidance of necrosis. To elucidate this point, PMA-induced superoxide generation was measured as cytochrome $c$ reduction activity. We observed that PMNs produced superoxides to a similar extent in the presence or absence of hemopexins. The rate of cytochrome $c$ reduction, measured as increase in absorbance at $550 \mathrm{~nm}$ per min, in the presence or absence of $1 \mathrm{mg} / \mathrm{ml}$ hemopexins was 0.00960 and 0.00884 , respectively (single measurement, representative of several experiments). This result suggests that hemopexins do not impair the stimulation of PMNs by PMA.

The incubation medium we used for cell incubation with PMA contained $40 \mathrm{mg} / \mathrm{ml}$ of BSA. Consequently, we examined whether the presence of BSA is a prerequisite for the suppression by hemopexin of PMA-induced necrosis. As shown in Fig. 5a, in the absence of BSA, hemopexins (1 $\mathrm{mg} / \mathrm{ml}$ ) alone could not suppress necrosis. BSA promoted the suppressive activity of hemopexins in a dose-dependent fashion. Human serum albumin (HSA) could also support the necrosis-suppressive activity of hemopexins (data not shown). Moreover, we found that bovine fetuin, a serum non-albumin protein, and the non-protein macromolecule dextran (MW 66700) also had promoting effects (Fig. 5b). The results suggest that albumin is not essential for the suppression by hemopexin of PMA-induced necrosis of PMNs, but that other macromolecules may be substituted. Although the precise role of these supportive molecules is unknown,

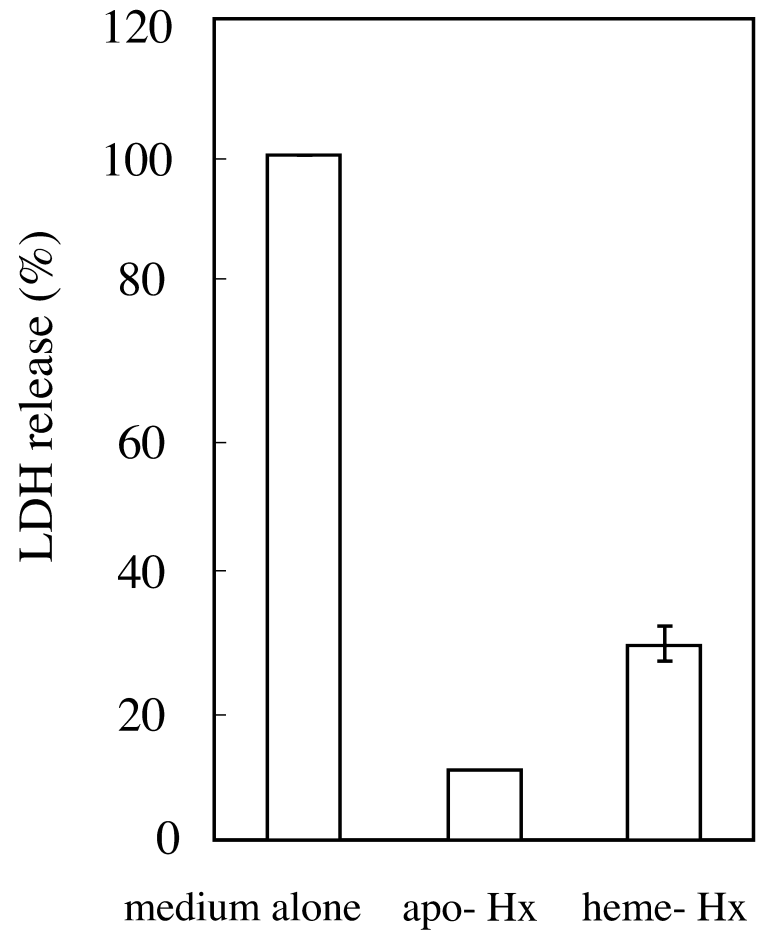

Fig. 4. Effect of heme on necrosis-suppressing activity of hemopexin. Cells were suspended in $1.0 \mathrm{mg} / \mathrm{ml}$ of apo-hemopexins (apo-Hx) or hemopexins preloaded with hemin chloride (heme-Hx) as described in the text. Cell viability was assessed by the LDH assay after exposure to $100 \mathrm{ng} / \mathrm{ml}$ PMA for 5 hours. Results were expressed as mean \pm SD of three separate experiments.

they may contribute to "cell stability" in the serum-free culture conditions, possibly by their osmotic pressure. We did not study this effect further.

In this study, as described above, serum (bovine, human and porcine) was shown to rescue porcine PMNs from the autotoxicity of PMA. We identified hemopexins as the necrosis-suppressing serum factor. Hemopexins suppressed PMA-induced necrosis of PMNs in a dose-dependent fashion (over the concentration range $0.1-1.0 \mathrm{mg} / \mathrm{ml}$ tested) in the presence of $40 \mathrm{mg} / \mathrm{ml}$ of albumin (Fig. 3). Hemopexins alone had no suppressive activity; the presence of another macromolecule was required (Fig. 5a and b). We also found that $\alpha$ - or $\gamma$-globulins have some necrosis-suppressing activity (data not shown). By immunoblot analysis using human anti-hemopexin antibodies, contamination with hemopexin was observed in commercially available human $\alpha$ - and $\gamma$ globulins (data not shown), so it is likely that the moderate necrosis-suppressing activities of these preparations are due in part to their hemopexin content. However, at present we cannot exclude the possibility that factors other than hemopexin with necrosis-suppressing activity also exist in these preparations.

As to how hemopexins inhibit necrosis of PMNs, it is necessary to elucidate the mechanism by which PMA in- 
a)

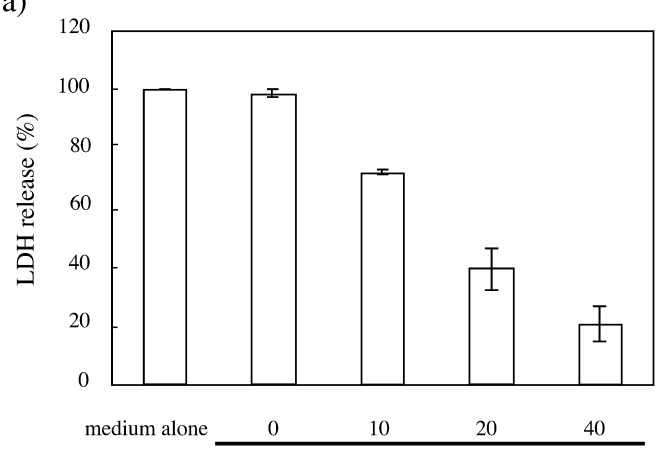

$\mathrm{BSA}(\mathrm{mg} / \mathrm{ml})+1 \mathrm{mg} / \mathrm{ml}$ hemopexins

b)

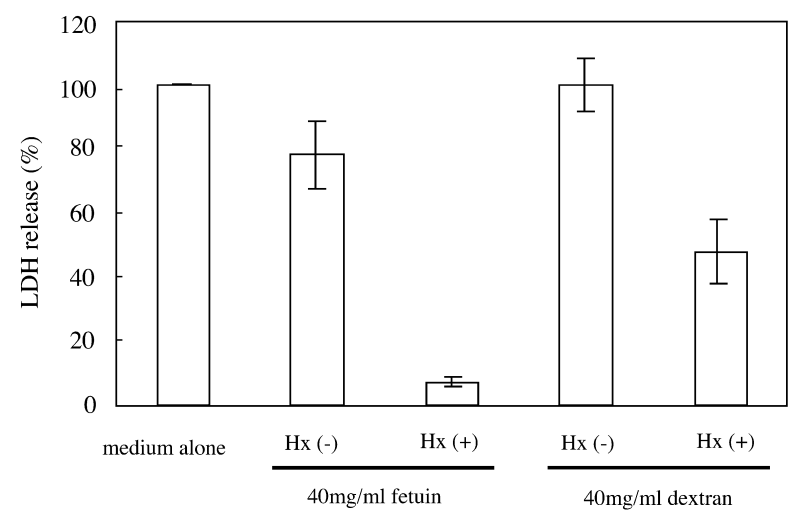

Fig. 5. Requirement of another macromolecule for suppression by hemopexin of PMA-induced PMN necrosis. Cells were exposed to $100 \mathrm{ng} / \mathrm{ml}$ PMA for 5 hours in the presence of $1.0 \mathrm{mg} / \mathrm{ml}$ hemopexin and a) various concentrations $(0,10,20$, and $40 \mathrm{mg} / \mathrm{ml})$ of BSA, or b) $40 \mathrm{mg} / \mathrm{ml}$ of fetuin or dextran. Viability was assessed by the LDH assay. Results are expressed as mean $\pm \mathrm{SD}$ of three separate experiments.

duces necrosis, and this is now under investigation. Our previous study showed that superoxide or $\mathrm{H}_{2} \mathrm{O}_{2}$ released by PMA-stimulated PMNs cannot induce self-necrosis (Suzuki and Namiki, 1998). Moreover, we observed that hemopexins suppressed PMA-induced necrosis although they did not inhibit PMA-stimulated superoxide production by PMNs. We also observed that an exogenous myeloperoxidase$\mathrm{H}_{2} \mathrm{O}_{2}$ system that produces about $1 \mu \mathrm{M}$ of $\mathrm{OCl}^{-}$did not induce PMN necrosis (unpublished data). However, because myeloperoxidase is a hemoprotein, there is a possibility that heme released from degraded myeloperoxidase is implicated in oxidative damage of PMNs, and that hemopexins may suppress it by trapping heme. According to our studies, however, this is unlikely. The molecular mechanism of the suppression by hemopexin of PMA-induced necrosis of PMNs is currently unknown, and our future studies will focus on elucidating this mechanism.

We emphasize in this paper that PMA has very strong toxicity for mature peripheral blood PMNs (Suzuki and Namiki, 1998). Nevertheless, Han et al. reported therapeutic effects of PMA in patients with myelocytic leukemia
(Han et al., 1998a; Han et al., 1998b). They reported that in most patients the levels of white blood cells and neutrophils increased by 24 hours after single intravenous administration of $0.25 \mathrm{mg}$ PMA, and that only mild and reversible side effects were observed. The concentration of PMA that they used would be high enough to induce necrosis of PMNs in vitro. It is highly possible that, in these patients given PMA, peripheral blood hemopexins rescued mature PMNs, such as neutrophils, from necrosis. However, if the blood hemopexin level of a leukemia patient is low or deficient, PMA administration may result in serious damage to mature PMNs.

Recently, Tolosano et al. (Tolosano et al., 1999) generated hemopexin-deficient mice by homologous recombination in embryonic stem (ES) cells. The hemopexin-deficient mice are viable and fertile. They showed that, although hemopexin is not crucial either for iron metabolism or for a protection against oxidative stress under physiologic conditions, it does play an important protective role after hemolytic processes. Deficiency of hemopexin in humans may normally be asymptomatic, since hemopexin-deficient mice are viable and fertile, so individuals with low blood hemopexin levels may not be uncommon. PMA is attractive as a therapeutic drug against leukemia, but we suggest that normal blood levels of hemopexin should be a prerequisite for treatment of these patients with PMA in order to avoid necrosis of mature PMNs.

Acknowledgments. We are greatly indebted to Dr. K. Furuishi and his colleagues (Applied Biosystems Japan, Tokyo) for protein N-terminal amino acid sequencing.

\section{References}

Aihara, H., Asaoka, Y., Yoshida, K., and Nishizuka, Y. 1991. Sustained activation of protein kinase $\mathrm{C}$ is essential to HL-60 cell differentiation to macrophage. Proc. Natl. Acad. Sci. USA, 88: 11062-11066.

Balla, G., Vercellotti, G., Eaton, J.W., and Jacob, H.S. 1990. Heme uptake by endothelium synergizes polymorphonuclear granulocyte-mediated damage. Trans. Assoc. Am. Physicians, 103: 174-179.

Curnutte, J.T., Kuver, R., and Babior, B.M. 1987. Activation of the respiratory burst oxidase in a fully soluble system from fuman neutrophils. $J$. Biol. Chem., 262: 6450-6452.

Guigui, B., Rosenbaum, J., Préaux, A.M., Martin, N., Zafrani, E.S., Dhumeaux, D., and Mavier, P. 1988. Toxicity of phorbol myristate acetate-stimulated polymorphonuclear neutrophils against rat hepatocytes. Lab. Invest., 59: 831-837.

Gutteridge, J.M.C. and Smith, A. 1988. Antioxidant protection by haemopexin of haem-stimulated lipid peroxidation. Biochem. J., 256: 861-865.

Han, Z.T., Zhu, X.X., Yang, R.Y., Sun, J.Z., Tian, G.F., Liu, X.J., Cao, G.S., Newmark, H.L., Conney, A.H., and Chang, R.L. 1998a. Effect of intravenous infusions of 12-O-tetradecanoylphorbol-13-acetate (TPA) in patients with myelocytic leukemia: preliminary studies on therapeutic efficacy and toxicity. Proc. Natl. Acad. Sci. USA, 95: 5357-5361.

Han, Z.T., Tong, Y.K., He, L.M., Zhang, Y., Sun, J.Z., Wang, T.Y., Zhang, H., Cui, Y.L., Newmark, H.L., Conney, A.H., and Chang, R.L. 1998b. 12- $O$-Tetradecanoylphorbol-13-acetate (TPA)-induced increase in depressed white blood cell counts in patients treated with cytotoxic cancer 
chemotherapeutic drugs. Proc. Natl. Acad. Sci. USA, 95: 5362-5365.

Majuri, R. 1982. Purification of pig serum haemopexin by haeminsepharose affinity chromatography. Biochim. Biophys. Acta, 719: 53-57.

Muller-Eberhard, U. 1988. Hemopexin. Meth. Enzymol., 163: 536-565.

Noiva, R., Pete, M.J., and Babin, D.R. 1987. Bovine serum hemopexin: properties of the protein from a single animal. Comp. Biochem. Physiol., 88B: $341-347$.

Okazaki, H., Taketani, S., Kohno, H., Tokunaga, R., and Kobayashi, Y. 1989. The hemopexin receptor on the cell surface of human polymorphonuclear leukocytes. Cell Struct. Funct., 14: 129-140.

Olsen, K.W. 1986. Affinity chromatography of heme-binding proteins: synthesis and characterization of hematin- and hematoporphyrinagarose. Meth. Enzymol., 123: 324-331.

Qin, S. and Yamamura, H. 1997. Up-regulation of syk activity during HL60 cell differentiation into granulocyte but not into monocyte/ macrophage-liniage. Biochem. Biophys. Res. Commun., 236: 697-701.

Shimizu, N., Ohta, M., Fujiwara, C., Sagara, J., Mochizuki, N., Oda, T., and Utiyama, H. 1991. Expression of a novel immediate early gene during 12-O-tetradecanoylphorbol-13-acetate-induced macrophagic differentiation of HL-60 cells. J. Biol. Chem., 266: 12157-12161.

Smith, A. and Morgan, W.T. 1985. Hemopexin-mediated heme transport to the liver: evidence for a heme-binding protein in liver plasma membranes. J. Biol. Chem., 260: 8325-8329.

Smith, A., Eskew, J.D., Borza, C.M., Pendrak, M., and Hunt, R.C. 1997. Role of heme-hemopexin in human T-lymphocyte proliferation. Exp. Cell Res., 232: 246-254.

Strop, P., Borvák, J., Kasicka, V., Prusík, Z., and Morávek, L. 1981. Isolation of human haemopexin by bioaffinity chromatography on haeme-sepharose. J. Chromatogr., 214: 317-325.
Suttnar, J., Hrkal, Z., Vodrázka, Z., and Rejnková, J. 1979. Haemesepharose $4 \mathrm{~B}$ as a chromatographic matrix for the isolation of haemopexin from human serum. J. Chromatogr., 169: 500-504.

Suzuki, K. and Namiki, H. 1998. Phorbol 12-myristate 13-acetate induced cell death of porcine peripheral blood polymorphonuclear leucocytes. Cell Struct. Funct., 23: 367-372.

Takahashi, N., Takahashi, Y. Heiny, M.E., and Putnam, F.W. 1985. Purification of hemopexin and its domain fragments by affinity chromatography and high-performance liquid chromatography. J. Chromatogr., 326: 373-385.

Takahashi, N., Takahashi, Y., and Putnam, F.W. 1985. Complete amino acid sequence of human hemopexin, the heme-binding protein of serum. Proc. Natl. Acad. Sci. USA, 82: 73-77.

Taketani, S., Kohno, H., Naitoh, Y., and Tokunaga, R. 1987. Isolation of the hemopexin receptor from human placenta. J. Biol. Chem., 262: 8668-8671.

Tolosano, E., Hirsch, E., Patrucco, E., Camaschella, C., Navone, R., Silengo, L., and Altruda, F. 1999. Defective recovery and severe renal damage after hemolysis in hemopexin-deficient mice. Blood, 94: 39063914.

Tsutsui, K. 1986. Affinity chromatography of heme-binding proteins: synthesis of hemin-agarose. Meth. Enzymol., 123: 331-338.

Wu, M.L. and Morgan, W.T. 1994. Conformational analysis of hemopexin by Fourier-transform infrared and circular dichroism spectroscopy. Proteins, 20: 185-190.

(Received for publication, June 1, 2001

and in revised form, August 6, 2001) 